\title{
ENSINAMENTOS DE SCHOPENHAUER QUE INFLUENCIARAM FREUD: A LOUCURA E O RECALQUE
}

\author{
Mateus de Freitas Barreiro
}

Universidade Estadual Paulista, Faculdade de Filosofia e Ciências - UNESP. Programa de Pós-Graduação em Educação, Marília - SP. E-mail: mateusfbb@bol.com.br

\section{RESUMO}

O objetivo deste trabalho é estudar o surgimento da psicanálise de Freud em contato com a filosofia de Schopenhauer. Não se conhece com profundidade a contribuição da filosofia na construção da teoria psicanalítica, desenvolvida por Freud. Este artigo visa levantar discussões sobre Schopenhauer, como educador de Freud, na construção de sua teoria. Para esta investigação toma-se como referencial as explicitações teóricas de Deleuze e Guattari (1992), sobre a formação do conceito em filosofia, para se estudar os ensinamentos entre o pensamento de Freud e Schopenhauer, no que tange à teoria da loucura e ao recalque. Este artigo investiga, em particular, as abstrações conceituais sobre o mecanismo de recalque, que representa uns dos principais conceitos da psicanálise.

Palavras- chave: Schopenhauer; Freud e ensinamentos.

\section{TEACHINGS OF THAT INFLUENCE SCHOPENHAUER FREUD: THE MADNESS AND REPRESSION}

\begin{abstract}
This work intent to study the influence of Schopenhauer's philosophy on the Freud's psychoanalysis. We don't know deeply, at the present moment, every philosophical influence on Freud, to development of this theory. This article aims to raise discussions on Schopenhauer as Educator of Freud, in the construction of his theory. For this investigation is taken as reference the theoretical clarifications of Deleuze and Guattari (1992), on the formation of the concept in philosophy, to study the teachings of Freud's thinking and Schopenhauer, regarding the theory of madness and repression. This paper investigates, in particular, the conceptual abstractions on the mechanism of repression, which represents the main concepts of psychoanalysis ones.
\end{abstract}

Keywords: Schopenhauer; Freud and teachings. 


\section{INTRODUÇÃO}

$\mathrm{O}$ artigo ${ }^{1}$ de pesquisa, Ensinamentos de Schopenhauer que influenciaram Freud: a loucura e o recalque foi elaborado a partir da preocupação de que não se conhece com profundidade a contribuição da filosofia na construção da teoria psicanalítica desenvolvida por Freud. Para se conhecer melhor tal contribuição é importante desenvolver estudos verticalizados que revelem as conexões entre a psicanálise de Freud e as obras dos filósofos por ele conhecidas e utilizadas. Neste artigo será investigado de que modo os ensinamentos da filosofia de Schopenhauer se fizeram presentes na obra de Freud. Tomando como referencial as explicitações teóricas de Deleuze e Guattari (1992) sobre a formação do conceito em filosofia, o estudo busca compreender como os conceitos de loucura e recalque foram construídos nas obras de Freud e Schopenhauer.

No final do século XIX, novos paradigmas fluem nos ares do horizonte cultural alemão, com Schopenhauer e Nietzsche, pois a razão já não ocupa mais um lugar soberano nas faculdades mentais do homem. As vontades e os instintos começam, então, a exercer uma preponderância irracional em processos que outrora eram considerados racionais. Há que se destacar que todo pensamento sempre expressa algo de sua cultura e de seu tempo, porém, os laços que unem Freud e Schopenhauer, estão interligados por elos mais fortes que o reflexo dos traços culturais.

Anterior a este século, na História da Filosofia não faltavam alusões a processos mentais não conscientes, sendo o incognoscível discutido por diversos filósofos. Entretanto este não era o eixo central de seus postulados, nem tampouco um tipo de pensamento que disparava grandes intensidades em seus meios culturais, embora tenha sido um dos elementos constitutivos para a construção de novos modos de pensar.

Primordialmente, a ideia schopenhaueriana sobre a loucura aparenta ter sua raiz apenas em especulações filosóficas, por se tratar de uma teoria não concisa e devidamente sistematizada. Contudo, a partir de documentos históricos resgatados por Zentner foi possível constatar que o fator que contribuiu para Schopenhauer fundamentar seu pensamento sobre a loucura, deu-se através de sua experiência empírica, ao entrar em contato com pacientes da ala psiquiátrica do hospital Charité em Berlim, que Schopenhauer passou a frequentar constantemente em 1811 (NEVES, 2002, p. 462). Em O Mundo como Vontade e Representação, é possível encontrarmos indícios deste contato de Schopenhauer com pacientes do hospital Charité, quando ele afirma: "visitei freqüentemente casas de alienados e encontrei aí sujeitos de um incontestável valor; o seu gênio manifestava-se distintamente

\footnotetext{
${ }^{1}$ Artigo proveniente da conclusão da pesquisa de iniciação científica fomentada pela Fundação de Amparo à Pesquisa do Estado de São Paulo - FAPESP. 
através da sua loucura tinha permanecido completamente dominante" (SCHOPENHAUER, 2004, p.201).

Ainda nesta obra, Schopenhauer (2004, p.203) discorre sobre a ideia de que a loucura emana de uma necessidade de esquecer e dissolver registros conscientes de experiências dolorosas adjacentes da realidade, tais como "violentas dores morais" e "acontecimentos terríveis". Para Schopenhauer (2004), o mecanismo da loucura advém quando um acontecimento extremamente árduo e angustiante para o indivíduo chega a atingir o seu limiar de tolerância e como resposta, a sua natureza recorre à loucura como "último recurso" para cessar estas dores. Assim "o espírito torturado rompe, por assim dizer, o fio da sua memória" (SCHOPENHAUER, 2004, p.203), permitindo ao indivíduo resgatar temporariamente sua integridade mental. Esta amnésia parte de um conflito entre a vontade e o intelecto e, se algum conteúdo for doloroso para a Vontade, esta evita que o Intelecto tome consciência de tal conteúdo.

Para Freud "a essência da repressão consiste simplesmente em afastar determinada coisa do consciente, mantendo-a à distância" (FREUD, 1996, p.171). Mas se tratarmos de um conceito tomando como sua perspectiva de descrição e análise, uma noção focada em sua essência, a sua compreensão não abrangeria suas multifaces, seus caminhos percorridos ao longo de sua história, seu processo de criação enquanto estava se constituindo, e o seu devir. Pensando o recalque sob várias ópticas diz Freud que "devemos estar preparados para encontrar uma multiplicidade semelhante de mecanismos de irrupção (ou de formação de sintomas), e já podemos começar a suspeitar que não será possível remontar todas essas multiplicidades somente à história desenvolvimental da libido" (FREUD,1996, p.75).

Após o breve comparativo entre os autores, o objetivo maior deste artigo é o de conhecer aspectos importantes da conjunção de Freud com a filosofia, em cujo centro está o pensamento de Schopenhauer, o filósofo mais citado por Freud.

\section{METODOLOGIA}

A primeira questão metodológica a ser colocada é a de que não objetivamos neste artigo questionar se as descobertas de Freud já haviam sido antes reveladas por Schopenhauer, enfocando a questão da originalidade ou não da psicanálise freudiana. Pretendemos isto sim, tomar como referencial teórico as explicitações de Deleuze e Guattari (DELEUZE, 1992, p. 27-47), sobre a questão 
da formação do conceito em filosofia, para estudar como os conceitos de loucura, recalque e vontade, são construídos nas obras de Freud e Schopenhauer.

Segundo Deleuze e Guattari, todo o conceito tem uma história, embora sua história se desdobre em ziguezague e cruze talvez outros problemas ou outros planos diferentes. Sob esse ponto de vista, o conceito apresenta-se, na maioria das vezes, "com pedaços ou componentes vindos de outros conceitos, que respondiam a outros problemas e supunham outros planos" (DELEUZE, 1992, p. 29). Por outro lado, do ponto de vista de seu devir um conceito mantem relação com outros conceitos, mas desta vez situados no mesmo plano. Aqui, afirmam Deleuze e Guattari, "os conceitos se acomodam uns aos outros, superpõem-se uns aos outros, coordenam seus contornos, compõem seus respectivos problemas, pertencem à mesma filosofia, mesmo se tem histórias diferentes. Com efeito, todo o conceito, tendo um número finito de componentes bifurcará sobre outros conceitos, compostos de outra maneira, mas que constituem outras regiões do mesmo plano, que respondem a problemas conectáveis, participam de uma co-criação" (DELEUZE, 1992, p. 30). A problemática levantada na construção do artigo é que Freud desenvolveu a psicanálise com a contribuição das ideias de $O$ Mundo como Vontade e Representação.

Esta posição metodológica instrumentaliza-nos na tarefa de desvelar as eventuais conexões de Schopenhauer sobre Freud, bem como os respectivos planos de discussão que alimentavam a criação daqueles autores. Sabemos que esse desvelamento poderá ocorrer senão através do contato direto e prolongado com as obras e o tempo desses autores, cotejando-os, na medida do possível, com descrições detalhadas de situações, eventos, pessoas, interações e comportamentos observados, trechos ou íntegras de documentos, correspondências, atas ou relatórios, envolvendo os autores em questão. Com isso poderíamos identificar o que se oculta por detrás de sentimentos e valores e ir descobrindo aos poucos, as conexões e ressonâncias entre os pensamentos de Schopenhauer e Freud.

\section{RESULTADOS}

A conexão de Freud com o pensamento shopenhaueriano se estabelece por múltiplos pontos e formas de contato. Primeiramente, quando Freud estava desenvolvendo sua teoria psicanalítica, o pensamento de Schopenhauer estava impregnado no final do século XIX, e também era muito popular nos meios em que Freud freqüentava. Zentner reforça a ressalva de Rank ao evocar dados biográficos resgatados por Willian McGrath, em que descreve a inserção de Freud em um grupo 
composto por alunos, autodenominado de Clube de Leitura dos Estudantes Alemães de Viena entre os anos de 1873-1878; um dos principais autores estudado neste grupo é Schopenhauer (ZENTNER, 1995, apud ROTHE-NEVES, 2002).

A filosofia de Schopenhauer caminhou por múltiplas vias identificáveis e não identificáveis que transitaram nos pensamentos de Freud, pensamentos que também já estavam preenchidos por outros tipos de idéias e conhecimentos advindos de sua prática psicanalítica. Todas essas intersecções de saberes, evidentemente incluindo a metafísica Schopenhaueriana, permitiram tanto a Freud quanto a Schopenhauer fazerem parte da atmosfera de criação da teoria Psicanalítica. Nesta fusão de saberes interdisciplinares, a metafísica de Schopenhauer serviu como um alicerce que possibilitou a Freud construir sua teoria psicanalítica, mesmo que ocupe diferentes espaços e que vise diferentes objetivos dos ensinamentos filosóficos de Schopenhauer.

\section{DISCUSSÃO}

Na Conferência 35 de Novas Conferências, Freud comenta a respeito da diferença entre a filosofia e a psicanálise, dizendo que a primeira consiste em "uma construção intelectual que resolve de maneira unitária todos os problemas de nossa existência a partir de uma hipótese subsumida, na qual, por consequência, nenhuma questão resta aberta, e tudo o que retém nosso interesse encontra seu lugar determinado" (FULGÊNCIO, 2001, p.18, apud FREUD,1933/1955d, p.242) ${ }^{2}$. Mas o que próprio Freud pensa a respeito da intersecção da filosofia com a Psicanálise? Para Freud é possível compor a filosofia junto a Psicanálise?

O contraste de Freud com a filosofia envolve a ideia de um sistema de conhecimento, um ramo do saber, uma disciplina, a psicanálise. A aproximação com a filosofia deverá ser feita sempre tomando como referencia que a filosofia e a psicanálise propõem-se a atingir diferentes objetivos, mesmo que estejam entrelaçadas por alguns conceitos que visem responder a outras questões. Quando se trata desta interlocução de saberes, abarcando a relação de Freud com a filosofia na maioria das vezes o tema se remete à ambivalência ${ }^{3}$ de Freud em relação à filosofia, pois Freud negligencia a filosofia algumas vezes e em outras circunstâncias a reverencia pelo seu antigo desejo de ser filósofo. ${ }^{4}$

\footnotetext{
${ }^{2}$ Freud não se refere a um filósofo em especial no que diz respeito à visão unitária Filosofia em resolver problemas.

${ }^{3}$ Para Freud o delírio e o discurso filosófico funcionam de maneira parecida, pois em ambos a subjetividade articularia as palavras como se fossem coisas, não tendo a preocupação em submeter o discurso ao imperativo do teste da realidade (BIRMAN, 2003, p. 11).

4 "De maneira curta e grossa Freud afirmou que estava finalmente realizando o seu desejo de ser um filósofo com a invenção da psicanálise" (BIRMAN, p.12, 2003).
} 
Mas, o que se pode afirmar sobre essa relação de ambivalência com relação à Filosofia, em Freud?

Provavelmente essas questões não visavam solucionar problemas que perpassassem a prática psicanalítica, ou até mesmo resolver uma questão filosófica relevante. Fulgêncio (2001) faz um comentário construtivo a respeito da ambiguidade de Freud em relação à filosofia. Ele sugere que esta ambiguidade, não se refere à atuação eminentemente prática de Freud, pois este sempre se colocou na posição de cientista, buscando solucionar problemas empíricos, que exigiam especulação, mas seu objetivo final era resolver estes problemas e não a formulação de uma "visão de mundo", nem de verdades cristalizadas sobre mundo e o homem (FULGÊNCIO, 2001, p.19). O objetivo de Freud, então, não era responder a questões filosóficas, mas utilizar a filosofia para ajudar a criar seus conceitos psicanalíticos.

O conceito de loucura de Schopenhauer foi um dos alicerces que possibilitou a Freud constituir o conceito de recalque, para explaná-lo em seu devir, com seus respectivos pontos de vista, tópico, econômico e dinâmico. Através do conceito de loucura foi possível Freud abstrair além do que sua prática clínica Ihe trazia.

\section{CONCLUSÃO}

Com a presente pesquisa tivemos oportunidade de exercitar a aplicação dos conceitos de Deleuze para o entendimento das aproximações, distanciamentos e entrelaçamentos das formulações criadas por Schopenhauer e Freud. A inseparabilidade das zonas internas de comunicação que foram tratadas ao longo da pesquisa diz respeito entro o elo sobre o conceito de loucura e repressão. Mas toda esta configuração e combinação entre um conceito e outro, em particular, podem ser redefinidas e reordenadas por outras combinações. Com isso pudemos concluir que a metafísica e a psicanálise são sistemas distintos, porém seus conceitos podem ser co-criados pela continuidade entre suas ideias, mesmo que visem à resolução de outros problemas e ocupem outros territórios. Numa eventual continuidade desta pesquisa, talvez seja possível enfatizar ainda mais o fato de que o conhecimento se faz muitas vezes através do entrelaçamento de conceitos e problemas de teorias diferentes.

\section{REFERÊNCIAS}

BIRMAN, J. Freud \& a filosofia. Rio de Janeiro: Jorge Zahar, 2003. 
DELEUZE, G. / GUATTARI, F. O que é a filosofia? Trad. Bento Prado Júnior e Alberto Alonso Muñoz. Rio de Janeiro: Editora 34, 1992.

FREUD, S. Esboço de Psicanálise. Trad. Maria Aparecida Moraes Rego. Rio de Janeiro: Editora Imago, 2001.

. O ego e o id. Trad. José Octavio de Aguiar Abreu. Rio de Janeiro: Imago, 1997.

- Obras psicológicas completas de Sigmund Freud. Direção da edição, Jayme Salomão. Rio de Janeiro: Imago, 1996. Vol. I.

- Obras psicológicas completas de Sigmund Freud. Direção da edição, Jayme Salomão. Rio de Janeiro: Imago, 1996. Vol. III.

FULGÊNCIO, L. Comentários críticos das referências textuais de Freud a Kant. Psicologia, São Paulo: Universidade de São Paulo, v. 12, n. 1, 2001.

IANNACO, F. Schopenhauer e i pazienti della Charité di Berlino (1812-1813).IL Sogno della farfalla, Rivista di Psichiatria e Psicoterapia, Nuove Edizioni Romane: Roma, vol.4, 1998.

NEVES, R. R.; NEVES, A. F. das. Freude e o esquecimento de Schopenhauer em Die Flucht ins Vergessen, de Marcel Zentner. Psicologia : Reflexão e crítica. Porto Alegre: vol. 15, no. 2, 2002. p. 461-464.

ROTHE-NEVES, R.; NEVES, A. Freud e o esquecimento em Die Flucht ins Vergegessen, de Marcel Zentner. Psicologia: Reflexão e Crítica. vol.15, no.2, 2002. p. 461 - 464. http://dx.doi.org/10.1590/S0102-79722002000200022

SCHOPENHAUER, A. O mundo como vontade e representação. $2^{\text {a }}$. ed.,Trad. M. S. Sá Correia. Rio de Janeiro: Contraponto, 2004. 